\title{
Integrated primary care in an integrated Europe
}

Once upon a time, in the last century, we all thought that general medical practice was primary care. The two seemed synonymous, and in the United Kingdom general practitioners even gave the name of their profession to the buildings, which hosted their consultations with patients. Once upon a time, even into the present century, we all thought of a health service as a national system. In the United Kingdom again the initials National Health Service (NHS) actually became the symbolic expression of collective State policy in society. Now, for both the meaning has radically changed, with primary care understood as intrinsically multi-professional and health systems increasingly required to be internationally significant. Moreover, the two new meanings progress hand in hand, with for example, models of inter-disciplinary managed care and community governance from the North and South Americas, simply the best known illustrations of organisational processes imported and adapted by the likes of Italian primary care groups, English practice-based commissioning clusters and Polish and Slovakian polyclinics.

With the global advance of the concept of Integrated Care the international exchange is further accelerating. Opportunities exist to extend and combine medical and other health services within primary care settings and, thereby, potentially address more fully the spectrum of problems that patients bring to a range of primary care providers. However, those with the interests of generalist lifelong primary care at heart need to be wary; not of the concept of Integrated Care per se - which can be a natural ally of primary health care based developments - but of outside influences that reduce the scale and strength of the lateral relationships, on which effective primary care and its networks rely. It is, therefore, important that those responsible for determining

Correspondence to: Professor Geoffrey Meads, Business School, University of Winchester, Hampshire SO22 4NR, UK. Email: g.d.meads@warwick.ac.uk

(C) Cambridge University Press 2010 the formative practices and polices of primary care are discerning in their selection of overseas sources for transferable learning. For instance, many managed care mechanisms tend to favour vertical rather than horizontal integration. The promotion of shared clinical protocols and case management, under the banner of Evidence Based Medicine, may have its origins traced back to marketing by life sciences companies in the United States that target large institutional customers, and their opinion forming lead hospital specialists.

It is against this background that the discourses of emergent and extended European social policy are becoming more important. These have the potential to not merely counterbalance negative influences from across the Atlantic, but also to ensure that multi professional and community based integrated care is firmly rooted in primary health service settings. One key route for achieving this goal is through incorporating such an approach more firmly in European social policy. The enlarged European Union has continued to guarantee high levels of social protection since the 1957 Treaty of Rome. The extension of such guarantees to include integrated care sourced from primary care settings may, for example, require the shared equity and capital ownership of frontline health services. Future case law and European Commission regulatory directions might then offer a real prospect of both enhanced multi-professional contributions and a wider community of interests and investors in primary care. Such measures as these at cross-continent levels offer the best practical opportunity of successfully addressing exclusive professional monopolies and restrictive practices for many countries in both Western and Eastern Europe. As a recent Position Paper from the European Forum for Primary Care highlighted (Meads, 2009a), these have left such countries as Hungary and Ireland with little alternative to the now outmoded and - in terms of the major community health agendas for early prevention and chronic disease management - dysfunctional small 'cabinet' 
or solo medical office organisational option. It is reasonable to expect that, over time, such States as these will argue for a much narrower definition of 'the general interest' clause, which at present facilitates the exemption of, for example, individual health care professions, as 'public law bodies' from the terms of the relevant European Articles (81 and 128 ) on the rights to establish the provision of services and free competition across a common market (Kent, 2006; Sauter and Schepel, 2009).

A common trend in recent health care reforms across many member states is the focus on more coordinated and integrated forms of provision; however, a lack of common terminology complicates 'discourse and application' (Grone and Garcia-Barbero, 2001). Integration when defined as comprehensively as in the following statement is a seductive term for European policy makers: to make it distinctively their own apart from more restricted national and American interpretations:-

Integration is a coherent set of methods and models on the funding, administrative, organisational, service delivery and clinical levels designed to create connectivity, alignment and collaboration within and between cure and care sectors.......cutting across multiple services, providers and settings (Kodner and Spreewenberg, 2002, p. 3).

For primary care to take full advantage of varied aspects of the integrated care movement, however, requires a significant shift in present approaches to research and development, and to European institutions. The former remains overwhelmingly domestic in its perspectives with hierarchic and bureaucratic reporting mechanisms. The latter is now quite the opposite, with its 'Open Method of Coordination' all about the interplay of countervailing horizontal and vertical forces, which emphasise both cooperation and imitation, as well as competition and diversity (Chalmers and Lodge, 2003).

The European institutions represent in themselves an exemplar 'integrationist project' (McCormick, 2002). This status is derived from the development of organisational processes that not only bring together 27 countries in membership, but also enable shared but complex decision making on policy through all the modern dimensions of democratic authority. The European Council and its Commission may be understood, accordingly, as representing the 'Union of States', the European
Parliament as the 'Union of Peoples' and the European Court as the 'Union of Laws' (Judge and Earnshaw, 2003). Historically, the Council has been dominant, and its pre-eminence has favoured free market oriented economic programmes over social policy, with, for a period, the Commission combining Health and Consumer Protection in a single directorate. This balance of power has not favoured modern primary care, although it has better suited the political interests of individual medical professions. Incrementally, however, the balance has been moving in the direction of both Public Health and the elected European Parliament. As with the apparent exclusion of the European Union (EU) from national health care systems under the Maastricht treaty 'Subsidiarity' principle in 1992, there has been a steady increase in the co-decision making and legislative rights of the Parliament, and a revival in interest in Article 11 of the Social Charter, which seeks to guarantee the right to health for all European citizens as a result. EU health systems and health policies are, therefore, becoming more interconnected, influenced not only by institutional and political factors, but also by such social influences as the movement of patients and professionals - facilitated by rulings of the European Court of Justice and the convergence of public expectations across the enlarged Union. The popular and cross-border causes that SARS and Swine Flu outbreaks represent have further widened participation in European policy-making processes. This increased interconnectivity raises important policy issues, not least those relating to quality in cross-border health care and how to reconcile national policies with European obligations in general.

All of which is good news for proponents of primary health care and the principle of Integration. Both stand to benefit from European social policies and regulations explicitly geared to principles of equity, prevention and protection within the frameworks of a regulated social market and without restraints of trade. Recent research has demonstrated the deficits in integrated care initiatives in The Netherlands and England (Crump, 2009; Van der Feltz-Cornelis, 2009), as well as the risks attached to the expansion of managed care enterprises across Europe (Meads, 2009b). It is therefore important that a rigorous future research and development agenda for primary care gives priority to international collaborations; to dissemination 
strategies that effectively respond to the diverse but increasingly influential European social policy community; and above all to identifying, examining and then sharing the learning about alternative organisational models. The future of European primary care may be then shown to be as much about the skills mix and services of a Macedonian Health Home, Slovenian multi-clinician (primary care) patient registration or a Finnish municipal health and community centre, as the past has been about a standard Dutch, Belgian or British general medical practice.

$$
\begin{array}{r}
\text { Professor Geoffrey Meads } \\
\text { Business School, University of Winchester } \\
\text { Hampshire, UK } \\
\text { Dr Sara Shaw } \\
\text { Senior Research Fellow, Nuffield Trust } \\
\text { London, UK }
\end{array}
$$

\section{References}

Chalmers, D. and Lodge, M. 2003: The open method of coordination and the European Welfare State. London: LSE
Centre for the Analysis of Risk and Regulation, discussion paper no. 11.

Crump, H. 2009: Can integration usher in a new age of risk taking? Health Service Journal 119, 12-13.

Grone, O. and Garcia-Barbero, M. 2001: Integrated care: a position paper of the WHO European Office for Integrated Health Services. International Journal of Integrated Care 1, e21.

Judge, D. and Earnshaw, D. 2003: The European Parliament. Basingstoke: Palgrave.

Kent, P. 2006: Nutcases. European Union Law. London: Sweet and Maxwell.

Kodner, D. and Spreewenberg, C. 2002: Integrated care: meaning, logic, applications and implications - a discussion paper. International Journal of Integrated Care 2, e12.

McCormick, J. 2002: Understanding the European Union. Basingstoke: Palgrave.

Meads, G. 2009a: The organisation of primary care in Europe: trends. Quality in Primary Care 17, 143-53.

Meads, G. 2009b: The organisation of primary care in Europe: agenda. Quality in Primary Care 17, 225-34.

Sauter, W. and Schepel, H. 2009: State and market in European Union Law. Cambridge: Cambridge University Press.

Van der Feltz-Cornelis, C. 2009: Towards integrated primary health care for depression disorder in the Netherlands. International Journal of Integrated Care 9, e83. 